Illinois State University

ISU ReD: Research and eData

Theses and Dissertations

4-13-2014

\title{
The Effects of Focality of Processing and Delay on Event-Based Prospective Memory
}

Samantha Nicole Petrella

Illinois State University, petrellas@icloud.com

Follow this and additional works at: https://ir.library.illinoisstate.edu/etd

Part of the Psychology Commons

\section{Recommended Citation}

Petrella, Samantha Nicole, "The Effects of Focality of Processing and Delay on Event-Based Prospective Memory" (2014). Theses and Dissertations. 230.

https://ir.library.illinoisstate.edu/etd/230

This Thesis is brought to you for free and open access by ISU ReD: Research and eData. It has been accepted for inclusion in Theses and Dissertations by an authorized administrator of ISU ReD: Research and eData. For more information, please contact ISUReD@ilstu.edu. 


\title{
THE EFFECTS OF FOCALITY OF PROCESSING AND DELAY ON EVENT-BASED PROSPECTIVE MEMORY
}

\author{
Samantha N. Petrella
}

41 Pages

December 2014

The current experiment proposed an examination of the effects of focality of processing and delays on event-based prospective memory tasks. According to the PAM theory (Smith, 2007), prospective memory performance requires resource-demanding preparatory attentional processes, while the MP view (Einstein \& McDaniel, 2000) states that prospective memory retrieval can occur spontaneously in some cases in the absence of monitoring. Lastly, the TAP view (Morris, Bransford, \& Franks, 1977) states that memory is enhanced when similar processing occurs during the study and test phases. To examine these three perspectives, we used three distinct ongoing tasks, which consisted of a focal-match condition (i.e., identify types of fish among true/false sentence verification tasks), a non-focal match condition (i.e., identify types of fish among living/non-living judgments), and finally a non-focal mismatch condition (i.e., identify types of fish among identifying if a word had more than one vowel). Additionally, we manipulated these conditions across various timing delays to evaluate conditions in which monitoring should not occur due to the length of time between the PM instruction and the PM cue presentation. The results showed that the overall PM accuracy for all PM task subjects decreased considerably with delay and that subjects had higher PM accuracy 
in the Non-Focal Match conditions compared to the Non-Focal Mismatch conditions, which strongly supports the TAP view of prospective memory. Further, monitoring was observed at all delay intervals (i.e., observed significant differences between no PM control and PM task conditions) showing constant, focused attention towards the PM task. Explanations for these findings are offered as well as implications and future directions for this research. 


\title{
THE EFFECTS OF FOCALITY OF PROCESSING AND DELAY ON EVENT-BASED PROSPECTIVE MEMORY
}

SAMANTHA N. PETRELLA

\author{
A Thesis Submitted in Partial \\ Fulfillment of the Requirements \\ for the Degree of \\ MASTER OF SCIENCE \\ Department of Psychology \\ ILLINOIS STATE UNIVERSITY
}




\section{THE EFFECTS OF FOCALITY OF PROCESSING AND DELAY ON EVENT-BASED PROSPECTIVE MEMORY}

SAMANTHA N. PETRELLA

COMMITTEE MEMBERS:

Dawn M. McBride, Chair

J. Cooper Cutting 


\section{CONTENTS}

Page

CONTENTS

TABLES

FIGURES $\quad$ iv

CHAPTER

I. THE PROBLEM AND ITS BACKGROUND 1

PM Tasks in the Laboratory $\quad 2$

Theoretical Perspectives 3

Analysis of Perspectives $\quad 9$

Delay Effects in Prospective Memory 11

$\begin{array}{ll}\text { The Current Study } & 13\end{array}$

$\begin{array}{ll}\text { II. METHOD } & 16\end{array}$

$\begin{array}{ll}\text { Participants } & 16\end{array}$

Design 16

$\begin{array}{ll}\text { Ongoing Tasks } & 17\end{array}$

$\begin{array}{ll}\text { Materials } & 17\end{array}$

$\begin{array}{ll}\text { Procedure } & 18\end{array}$

$\begin{array}{ll}\text { Focal Match Condition } & 18\end{array}$

$\begin{array}{ll}\text { Non-Focal-Match Condition } & 18\end{array}$

Non-Focal Mismatch Condition $\quad 19$

$\begin{array}{ll}\text { PM Task } & 19\end{array}$

PM Cue Presentation 19

$\begin{array}{ll}\text { III. RESULTS } & 21\end{array}$

PM Task Accuracy 21

Ongoing Task Accuracy $\quad 24$

Ongoing Task Reaction Times 24

$\begin{array}{ll}\text { IV. GENERAL DISCUSSION } & 32\end{array}$

Paramount Findings $\quad 32$ 
REFERENCES 


\section{TABLES}

Table

Page

1. Mean prospective memory accuracy for ongoing task by delay conditions

2. Mean Baseline Block reaction times for ongoing task by delay conditions

3. Adjusted means of PM Block reaction time for ongoing task by delay 28

4. Adjusted means of PM Block reaction times by ongoing task

5. Adjusted means of PM Block reaction times by delay

6. Post hoc analyses for mean difference of PM Block reaction time data by ongoing task, $* \mathrm{p}<.05$

7. Post hoc analyses for mean difference PM Block reaction time data by delay, $* \mathrm{p}<.05$ 


\section{FIGURES}

Figure $\quad$ Page

1. Prospective Memory Accuracy for Ongoing Task by Delay 22

2. Prospective Memory Accuracy by Ongoing Task, * p <.001 22

3. Prospective Memory Accuracy by Delay, $* p=.004$

4. Adjusted Means for Prospective Memory Block Reaction Times for $\begin{array}{ll}\text { Ongoing Task by Delay } & 26\end{array}$

5. Prospective Memory Block Reaction Times by Ongoing Task, ${ }^{*} \mathrm{p}<.00126$

6. Adjusted Means for Prospective Memory Block Reaction Times by Delay, $* \mathrm{p}<.001$ 


\section{CHAPTER I}

\section{THE PROBLEM AND ITS BACKGROUND}

Prospective memory (PM) is utilized when an individual needs to remember to complete a task at some point in the future (Einstein \& McDaniel, 1990). In order to do so, one must recognize specific cues within the environment to prompt them to perform the intended task. For example, one might leave a post-it note on his/her bathroom mirror which states "Milk, Bread, and Eggs" to remind them to go food shopping. When the post-it is seen, the individual realizes the post-it is a cue to go food shopping. Without prospective memory, a large majority of household chores, errands and duties could be forgotten about and never completed. In some cases, a prospective memory failure could result in forgetting a child at daycare or a patient forgetting to take his/her heart medication. Whether a prospective memory failure impacts an individual on a small scale, such as forgetting to pack a lunch for the day, or on a large scale, such as accidentally leaving a young child in the backseat of a car, it is essential to daily life to be able to form intentions for the future.

PM can include several types of tasks. Event-based PM is one type of PM involved when remembering to complete a specific task in the future after a cue has been presented (e.g., take medication before bed every single night). Time-based PM is a second type of PM which relies on time intervals between PM cue presentation and when the PM task should be performed (e.g., turn the light off in 2 minutes). Both event-based and time-based PM rely on the subjects' ability to remember to do something in the 
future (Einstein \& McDaniel, 1990; Einstein, McDaniel, Richardson, Guynn \& Cunfer, 1995).

\section{PM Tasks in the Laboratory}

A typical prospective memory experiment consists of multiple stages or blocks. These blocks are referred to as the baseline block (no PM task) and the PM block (PM task). In a simple experiment, each participant receives one set of instructions and completes a block of trials of a particular task; this is also known as the ongoing task (Einstein \& McDaniel, 2005). Since prospective memory is depended upon daily, an ongoing task is necessary to mimic in-vivo scenarios such as remembering to drop your child off at daycare, taking medication at the same time everyday, or picking up the dry cleaning after work, each of which must be remembered against a background of other daily, ongoing tasks such as driving to and from work, making dinner, etc. By replicating prospective memory tasks in the lab, it is easier to generalize the results on a simple computer experiment to these real-world scenarios.

In many PM experiments in the lab, following a baseline block, subjects are typically given a second block of ongoing task trials, which includes the previous baseline block instructions as well as a new prospective memory task instruction. After being given the PM instructions, the subjects may be given a distractor task, such as a Sudoku puzzle to complete, in order to keep their minds occupied and prevent rehearsal of the PM instructions. Finally, the subjects complete the prospective memory block, where they continue to complete the ongoing task trials with the additional PM task. PM task accuracy is the key dependent measure, but ongoing task speed and accuracy in this block are typically compared with the speed and accuracy in the baseline block to 
determine if the PM task adds a cost to the ongoing task the subject is performing. The presence of a PM cost to the ongoing task has been an important aspect of studies testing the different theoretical perspectives on PM.

\section{Theoretical Perspectives}

Several perspectives regarding the process of remembering to perform an intended action in the future have been proposed by researchers in this area. Smith (2007) proposed the Preparatory Attentional and Memory (PAM) process theory regarding PM. According to the PAM theory, the retrieval of a prospective memory continuously requires resource-demanding preparatory attentional processes, or effortful and deliberate focus. Further, it suggests that successful PM retrieval is never automatic and that attention to the PM task interferes with and compromises ongoing task performance (Smith, 2003). In other words, a PM cost to the ongoing task will always be present. Smith (2007) suggests that the PM cost may be caused by individuals monitoring, or seeking out, cues to aid in the completion of a PM task. This PM cost should be seen in terms of slower speed or lower accuracy on the ongoing task in return for a higher PM accuracy. According to the PAM perspective, this trade-off is predicted for any PM task, regardless of the connection between the PM and ongoing tasks.

There are numerous studies that have produced results in support of the PAM view. Park, Hertzog, Kidder, Morrell, and Mayhorn (1997) manipulated the type of task subjects completed in order to compare working memory alongside event-based and time-based PM performance. In this study, the working memory task was completed as the ongoing task in order to collect reaction time data and accuracy recordings.

Afterwards, subjects completed either the time-based or the event-based PM task. The 
subjects who completed the event-based PM task in addition to the working memory task had the slowest reaction times compared to the subjects who completed the time-based PM task and the control groups. The researchers concluded that a PM cost to the working memory task occurs when an event-based PM task is also completed. They were able to draw these conclusions because they examined both event-based as well as time-based PM tasks concurrently against a working memory task. This is relevant to the current study because event-based PM will be examined alone. Park et al. (1997) attributed these results to the higher-demand of attention with event-based PM tasks compared to timebased PM tasks. These results are termed a PM cost because the event-based PM task consumed the attentional resources of the subjects. Due to the subjects' conscious attention to the PM task, the ongoing working memory task suffered in speed. These results support the PAM view since attention allocation to a PM task produced a PM cost (Smith, 2003, 2007).

Burgess, Quayle, and Frith (2001) examined event-based PM as well. Subjects completed a baseline block of just an ongoing task followed by several blocks of the ongoing task with an embedded PM task. They measured the cost of adding the PM task by observing reaction time differences between blocks with only the ongoing task to blocks that included a PM task as well. They found that subjects struggled more with the experiment when asked to complete the PM task, resulting in slower reaction times (i.e., PM cost). These results are congruent with the PAM view in that the slowing of the reaction times was attributed to a PM cost. The rationale behind this conclusion is that the PM task consumes too much of the attention that needs to be devoted to the ongoing task (Smith, 2003, 2007). 
A comparative perspective to the PAM theory on prospective memory is the multi-process view (MP) first proposed by Einstein and McDaniel (2000). This view states that prospective memory retrieval can occur spontaneously in some cases in the absence of monitoring when a PM cue is presented. The PM cue prompts the subjects to spontaneously retrieve the PM task instruction, which does not require preparatory attention. For example, one might drive home from work needing to pick up milk from the market on the way. Noticing a cow on a billboard and spontaneously retrieving the intention to stop at the market to get milk illustrates this process. During this process, the cue (i.e., the cow on the billboard) prompted remembering the PM task of stopping to buy milk at the market.

A key aspect of the MP view is defining the conditions under which spontaneous retrieval can be relied upon for completion of the PM task. Einstein and McDaniel (2005) state that the focality of the PM task plays an important role in the use of spontaneous retrieval for successful PM task performance. A focal PM task is one in which "the ongoing task encourages processing of the $[\mathrm{PM}]$ target and especially those features that were processed at encoding” (Einstein \& McDaniel, 2005, p. 287). This refers to a match in relevant features of the stimuli for the ongoing and PM tasks. For example, if an individual is in the process of verifying the truth of short statements such as "A Toyota is a vehicle" and they are also asked to respond to types of Cars for the PM task, the task is focal in nature because processing the category of the items is necessary to complete the ongoing task and will allow one to notice that an item is a Car. According to the MP view, the processing of the relevant feature of the PM cue (in this case Cars) will allow someone to spontaneously retrieve the PM task when they identify an item as belonging 
to the Cars category. Conversely, if the ongoing task is non-focal to the PM task and does not involve processing the relevant feature of the PM cue (e.g., a lexical decision ongoing task where words must be identified among letter strings), the subject is more apt to monitor for the embedded cues, which will result in a cost to the ongoing task speed or accuracy, or show reduced performance on the PM task (Einstein et al., 2005).

Einstein et al. (2005) examined the MP view in a study of PM performance by placing a PM task within an ongoing task and predicted that spontaneous retrieval of the PM instruction would occur upon presentation of the target events (i.e., the PM cues). By manipulating the association between the ongoing and PM tasks, the number of PM cues, as well as the importance of the PM task itself, they found a PM cost (i.e., slower reaction time speed and decreased ongoing task accuracy) only in some conditions. They found this cost depended on the focality of the ongoing task, the manner in which the instructions are given, the number of PM cues, how long the ongoing task takes, and individual differences (Einstein et al., 2005). These results are important to PM research because they found that subjects could complete PM tasks with only spontaneous retrieval (e.g., compared to monitoring) in some cases. A PM cost occurred in conditions considered to be non-focal in nature, when the number of PM cues was high (i.e., 6 cues versus 1 cue), and when the PM task was emphasized over the ongoing task in the instructions. In contrast, no cost was found in the comparison condition (i.e., focal, 1 cue, ongoing task emphasized), which are predicted results of the MP view (Einstein et al., 2005).

Additionally, Scullin, Einstein and McDaniel (2009) found support for the MP view. By manipulating the instructions during the experiment, subjects were left to think 
they were finished or not finished with the PM task. It was hypothesized that those subjects in the not-finished conditions would be more likely to utilize spontaneous retrieval to boost PM performance; in return this would produce a reduction in speed on trials when the PM cues were presented in a block of trials where the PM task had been suspended. While a PM cost is a typical result of monitoring, in this case, spontaneous retrieval occurred. Scullin et al. (2009) argued that because the subjects were not expecting to complete the PM task within this block, there was no reason for them to monitor for the cues. In addition, their results showed that the reduction in speed only occurred on the trials where the PM cues were presented and not on matched control trials in this block. This supports the MP view because more subjects experienced spontaneous retrieval of the PM instructions in the not-finished condition than in the finished condition (where activation of the PM task should have ended), showing that when subjects expected to complete the PM task again in the experiment, they had to inhibit responding to the cues due to spontaneous retrieval of the PM task, which caused them to complete those trials more slowly.

Recently, Scullin, McDaniel and Shelton (2013) proposed a dynamic MP view, which spells out more specifically when monitoring might occur within an ongoing task (e.g., after a PM cue is noticed and the PM task is then spontaneously retrieved). They proposed that monitoring can occur when subjects expect to perform the PM task (e.g., at initial intention formation and after spontaneous retrieval of the task after a cue is presented) for a brief time and then it fades away; spontaneous retrieval can then take over between monitoring instances. This is an update to the view previously proposed by Einstein and McDaniel (2000). 
A third perspective on prospective memory processing is transfer-appropriate processing (TAP), originally proposed by Morris, Bransford and Franks (1977) for explicit memory retrieval. TAP is traditionally applied when addressing memory performance in typical memory experiments involving study and test episodes, but it has been applied to PM task performance in recent years. According to TAP, memory is enhanced when similar processing occurs during the study and test phases. When the TAP view is applied to PM, the view suggests that the degree of overlap in processing between the ongoing task and the PM task influences PM performance (Maylor, 1996). This overlap in processing prompts automatic processing of the PM target words. TAP predicts better PM performance when there is an overlap in processing (e.g., semantic processing) between the PM task and the ongoing task. For example, if both the ongoing task and the PM task require semantic processing, PM task performance should be high. Additionally, automatic processing of the key features of the PM cues could boost PM performance. Maylor (1996) stressed that a change in processing type between the study (i.e., the baseline block) and the test phase (i.e., the PM block) of the experiment is where subjects struggle the most on the PM task.

Meier and Graf (2000) examined TAP in prospective memory with semantic and perceptual processing in the ongoing and PM tasks. Results showed that when the ongoing and PM task involved either a semantic-semantic match in processing or a perceptual-perceptual match, participants had higher PM performance. Additionally, Abney, McBride, and Petrella (2013) also discovered a PM advantage when the type of processing was similar across the PM and ongoing tasks. The researchers examined the overlap in ongoing and PM task conditions, which created a match as well as a mismatch 
in processing. Furthermore, additional ongoing tasks were used to assess semantic and orthographic match conditions (i.e., TAP). Overall, the results demonstrated a PM cost in every condition, as well as a PM performance advantage with the match conditions compared to the mismatch conditions.

McBride and Abney (2012) examined both the TAP view and the Multi-Process (MP, Einstein \& McDaniel, 2005) view in regards to PM performance. Three separate conditions were manipulated to access both TAP and MP components to processing. These three conditions consisted of two non-focal conditions (one match and one mismatch condition) and one focal match condition (i.e., conceptual and perceptual ongoing and PM tasks). The results showed a PM advantage in the focal condition compared to the non-focal conditions (McBride \& Abney, 2012), supporting the MP view of PM performance. The manipulation of the TAP and MP view processing conditions serves as the strongest link to the current experiment, as these conditions are included in the current study to further test the MP and TAP views of MP.

\section{Analysis of Perspectives}

According to TAP, a match in processing boosts PM performance. According to the MP view, focal tasks improve PM performance. These two perspectives on PM performance can jointly help explain how imperative the type of processing is in PM performance. According to Morris et al. (1977), an overlap in processing is necessary between various categories of stimuli (e.g., semantic) for higher memory performance. This is similar to the focal conditions suggested by the MP view because in focal tasks there is an overlap or match in processing, which is present to aid PM performance. However, according to TAP, the same type of processing in the ongoing and PM tasks is 
sufficient to promote PM performance, whereas the MP view focuses more on how the overlap in features in the ongoing task and the PM cue promote PM performance (i.e., focality). In other words, one might consider a focal condition to be an extreme case of a match in processing between the PM and ongoing tasks.

In the current study, a match in processing and the focality of the items to be processed were manipulated simultaneously, similar to the manipulation included in the McBride and Abney (2012) study. By altering the nature of the ongoing tasks with a single PM task embedded in these ongoing tasks, PM performance was expected to change based on the degree of overlap in the tasks. A condition that is defined as both focal and includes a match in processing can be seen as the highest overlap across the tasks in that the ongoing task involves the same type of processing (i.e., semantic processing) as the PM task while also encouraging the processing of the relevant features of the PM cues. Conversely, a non-focal mismatch condition involves different types of processing across the tasks and, therefore, does not encourage attending to relevant features of the PM cues. Between these two extremes, a non-focal match condition can be created that involves the same type of processing, but is not focal in that the ongoing task does not involve processing the relevant features of the PM cues. For example, a focal match condition is created when the ongoing task and PM task use the same type of processing and the ongoing task requires processing of the relevant feature (e.g., the category) of the PM cues (e.g., identify types of fish among true/false category verification sentences). A non-focal match condition is created when the ongoing task and PM task use similar types of processing (e.g., identify types of fish among living/non-living judgments), but the ongoing task does not encourage processing the 
category of the items for categorical PM cues. A non-focal mismatch condition is created when the ongoing task and PM task use different types of processing (i.e., identify types of fish while identifying if a word has more than one vowel). By manipulating these conditions, the present study tested both the TAP and MP views simultaneously.

As McBride and Abney (2012) reported, a PM advantage can occur during focal match conditions. Thus, the current study provided a further comparison of these three conditions for both PM accuracy and PM cost across a range of delays to include conditions where monitoring should not occur (i.e., longer delays).

\section{Delay Effects in Prospective Memory}

According to Smith (2003), individuals will monitor for PM cues when given a PM task. Consistent with this idea, it could be expected that more monitoring will occur at the beginning of the block following the new PM instruction and taper off with time (i.e., longer delays). The dynamic PM view proposed by Scullin, McDaniel, and Shelton (2013) also supports the assumption that monitoring occurs when the presentation of the PM cues are expected.

Since monitoring is a resource-demanding mental process, it may not always be relied upon to complete various tasks. It can be considered maladaptive to continuously monitor for cues in the environment, which requires a considerable amount of conscious attention (Scullin, Einstein, \& McDaniel, 2009). If strategic monitoring were the only strategy utilized, PM task intentions would take a longer period of time to complete. Instead, it seems more likely that after a longer period of time, monitoring fades away and spontaneous retrieval kicks in, consistent with the MP view described above. By utilizing both monitoring and spontaneous retrieval, individuals are able to free up their 
conscious attention for other tasks while still remembering to do something in the future. Scullin, McDaniel, Shelton, and Lee (2010) found that different retrieval processes (e.g., monitoring and spontaneous retrieval) occur when presented with focal vs. non-focal PM cues. The results of this study revealed that successful retrieval of a PM cue is heavily dependent on monitoring for non-focal cues and not for focal cues. These results show that monitoring is not necessary for focal cues (Scullin et al., 2010).

McBride, Beckner and Abney (2011) examined whether delay effects were different depending upon the focality of the task. The assumption in this research was that if monitoring is expected to fade over time, PM performance should drop with a delay in just the non-focal condition if the MP view is correct or in both conditions simultaneously if the PAM view is correct. Their results specifically demonstrated that non-focal PM performance follows a predictable function in which there is a much faster decline in performance with shorter delays compared to the longer delays and that monitoring can decrease dramatically after just a short delay. In addition, they demonstrated that subjects completed the PM task faster in the focal conditions compared to the non-focal conditions, which shows that the focal conditions were easier to complete compared to the non-focal conditions, and no PM cost was present for the higher PM performance. Since no effect of delay was found when completing a focal task, McBride et al. (2011) provided support that monitoring is not necessary for high accuracy in the PM task for focal tasks. Further, their results demonstrated that in nonfocal conditions a non-linear forgetting function was observed; this is an interesting finding since forgetting in explicit memory tasks typically follows a nonlinear function such as an exponential or power function (Wixted \& Ebbesen, 1991). These results 
demonstrate that the majority of the forgetting occurs immediately after the subjects' initial intention formation and declines more slowly over time for non-focal tasks. This aspect of their results will be tested further in the current study with a manipulation of delay across the three ongoing task conditions.

\section{The Current Study}

The purpose of the current study was to determine if focality produces similar levels of PM accuracy to a match in processing. In other words, will focality elicit spontaneous retrieval when compared to the match/non-focal condition (i.e., is a focal condition a more extreme version of a match in processing or is a match in processing sufficient to produce an advantage in PM performance compared to mismatched processing conditions?)?

The current study was conducted to replicate the design used by McBride and Abney (2012) with different tasks and to address inconsistencies in the results. The main questions in the current experiment were (1) What is most important, focality or just a match in processing (MP and TAP views) and (2) What impact does delay have on PM cost? (PAM view). Additional questions to be considered included what the match condition will look like (i.e., is it going to show monitoring like mismatch or show no monitoring like focal?).

To evaluate the question previously stated, three distinct ongoing tasks were utilized as described above. These conditions consisted of a focal match condition (i.e., identify types of fish among true/false sentence verification tasks), a non-focal match condition (i.e., identify types of fish among living/non-living judgments), and finally a non-focal mismatch condition (i.e., identify types of fish among identifying if a word has 
more than one vowel). Additionally, these conditions were manipulated across various timing delays to evaluate conditions in which monitoring should not occur due to the length of time between PM instruction and PM cue presentation. A pilot study consisting of only the focal-match task, yielded results supportive of the findings of McBride and Abney (2012).

Based on the literature discussed previously (Einstein \& McDaniel, 2005; Scullin et al., 2010; McBride \& Abney, 2012; McBride et al., 2011; Smith, 2003, 2007), it was hypothesized that (1) overall PM accuracy would be highest in the focal/match conditions and to decline less with delay than the other conditions; this hypothesis is grounded in the MP view, which states that focal tasks should have higher PM performance (Einstein \& McDaniel, 2000), as well as the TAP view, which states that a match in processing should have higher PM performance, as well (Meiser \& Graf 2000).

Additionally, it was hypothesized that (2) the overall PM cost (e.g., ongoing task speed) would decrease with delay due to decreased monitoring in longer delays and to decrease most rapidly for the focal-match condition; while this result was not found by McBride and Abney (2012), it is still consistent with the MP view of PM. Since monitoring for a PM cue requires resource-demanding attention, it was expected to be used less during longer time intervals between PM instruction and PM cue presentation. In typical memory experiments, researchers can manipulate delay by having subjects complete a distractor task for a specific amount of time to prevent rehearsal of instructions. In the current experiment, we manipulated delay with the specific placement of the PM cues in the ongoing task after a set number of trials following the PM 
instruction. By manipulating delay, the effects of monitoring on the three conditions can be examined. 


\section{CHAPTER II}

\section{METHOD}

\section{Participants}

Undergraduate psychology students at a large Midwestern university participated in this study in exchange for course credit. After a power analysis using G*Power (Erdfelder, Faul, \& Buchner, 1996), anticipating a medium effect size Cohen's $f$ of 0.25 (Scullin et al., 2010), power set at .80 and an alpha of .05, the desired sample size for this experiment was 300 subjects ( $n=20$ per between-subjects condition), with 301 subjects' data analyzed with 20 per condition with the exception of one additional subject for the Living/Non-Living task and the No-PM control condition $(n=21)$.

\section{Design}

Each subject completed one of three ongoing task conditions: Focal Match, NonFocal Match, and Non-Focal Mismatch. The study consisted of two blocks: baseline and PM blocks. Each subject completed both blocks in the same order. In doing so, PM accuracy and PM cost (i.e., difference in reaction time between the two blocks) can be examined for each subject. The baseline block consisted of 55 target trials and 5 practice trials. The PM block consisted of 188 trials. Additionally, the four delay intervals between when the PM instruction appeared and when the PM cue appeared, as well as a no PM control for each ongoing task, were manipulated (refer to the PMCue Presentation section for more details regarding how delay was manipulated). 


\section{Ongoing Tasks}

The Focal Match condition consisted of the sentence verification task. The instructions asked the participants to read a short statement on the screen and to press "a" if the statement was true and "l" if the statement was false.

The Non-Focal Match condition consisted of a living/non-living judgment task. A single word appeared on the screen (i.e., desk, apple, cat etc.) and subjects pressed "a" if it was living and "l" if it was non-living.

The Non-Focal Mismatch condition consisted of a vowel identification task in which subjects identified if a word had more than one vowel. If a word had more than one vowel, they pressed the "a" key. If a word did not have more than one vowel, they pressed the "l" key.

Lastly, control conditions were used omitting the PM task to compare reaction time and accuracy results. A separate control condition was used for each of the three ongoing tasks. In doing so, we can determine if monitoring occurred during the PM conditions by comparing reaction times across the blocks.

\section{Materials}

The stimuli consisted of 252 words, presented either alone or placed within short sentences, taken from a category norms list (Van Overschelde, Rawson \& Dunlosky, 2003). The same words were used in all ongoing task conditions. In addition, four types of fish (i.e., cod, shark, tuna, and salmon) were used as prospective memory cues within the stimulus list. Words were assigned to baseline and PM blocks such that all PM cues occurred on only "no" trials during the sentence verification task to prevent the category word "fish" from prompting the PM intention in the sentence verification task. 


\section{Procedure}

One at a time, each subject came into the lab, was given an informed consent to sign, and sat at the computer. Before beginning the computer-based experiment, the experimenter explained the instructions thoroughly and asked if the subject had any questions before proceeding. Each subject completed one of the three ongoing tasks for the duration of the experiment in addition to the PM task.

\section{Focal Match Condition}

For the Focal Match condition, subjects completed a sentence verification task as the ongoing task. The experimenter read aloud the instructions on the computer screen, which instructed the subject to read each short statement presented on the screen and to decide if it was a true or false statement. Before each statement, a "+" sign appeared, serving as a fixation point, for a duration of $500 \mathrm{~ms}$. If the statement presented was a true statement, the subject was instructed to press the "a" key on the keyboard. If the statement presented was a false statement, the subject was instructed to press the "l" key on the keyboard.

\section{Non-Focal Match Condition}

For the Non-Focal Match condition, subjects completed a living/non-living judgment task as the ongoing task. The experimenter read aloud the instructions on the computer screen, which prompted them to read each word presented on the screen and to decide if it was a living or non-living object. Before each word, a "+" sign appeared, serving as a fixation point, for a duration of $500 \mathrm{~ms}$. If the word presented was a living object, the subject was instructed to press the "a" key on the keyboard. If the word 
presented was a non-living object, the subject was instructed to press the "l" key on the keyboard.

\section{Non-Focal Mismatch Condition}

For the Non-Focal-Mismatch condition, subjects were asked to determine the number of vowels within each word as the ongoing task. The experimenter read aloud the instructions on the computer screen specifying the subject to read each word presented on the screen and to decide if it had more than one vowel within the word. Before each word, a "+" sign appeared, serving as a fixation point, for a duration of $500 \mathrm{~ms}$. If the word presented had only one vowel, the subject was instructed to press the "a" key on the keyboard. If the word presented had two or more vowels, the subject was instructed to press the "l" key on the keyboard.

\section{PM Task}

After completing one of the three ongoing tasks in the baseline block, the subjects encountered a second set of instructions. The experimenter then introduced the PM task, which the subject completed in addition to the ongoing task they completed earlier; every subject completed the same PM task, regardless of which ongoing task they completed. For the second half of the experiment (i.e., PM Block), the subjects needed to press the "Q" key whenever a type of fish was presented on the screen in addition to completing the ongoing task.

\section{PM Cue Presentation}

The PM cues appeared in blocks of 10 trials of the ongoing task at various delay intervals approximated at $30 \mathrm{~s}$ (first PM cue appeared on the $14^{\text {th }}$ trial), 1 min (first PM cue appeared on the $29^{\text {th }}$ trial), 3 min (first PM cue appeared on the $111^{\text {th }}$ trial), and 5 min 
(first PM cue appeared on the $160^{\text {th }}$ trial) after the PM instruction. A total of 4 PM cues were presented, with the other three PM cues presented on the same trials across the ongoing tasks within 10 trials of the first appearance of the first PM cue. Thus, for the 30 s delay, the last PM cue was presented by the $24^{\text {th }}$ trial of the ongoing task. After the PM block, the experimenter asked, "What were your tasks?" and wait for the subject to mention pressing the "Q" key when encountering types of fish. The subject was prompted about the PM task ("Were there any other tasks?") if they did not mention the PM task after the first question. Any non-control subjects who did not remember the PM task at the end of the experiment were replaced to ensure that PM task failures did not reflect retrospective memory failures. The experimenter thoroughly debriefed every subject on the purpose of the experiment. 


\section{CHAPTER III}

\section{RESULTS}

\section{PM Task Accuracy}

In order to assess the differences in PM accuracy in regards to the type of ongoing task and delay manipulation, a two-way between-subjects ANOVA was conducted; Table 1 and Figure 1 present the accuracy means from this analysis. The results showed a highly significant main effect of ongoing task, $F(2,240)=7.98, p<.001 \eta_{\mathrm{p}}{ }^{2}=.065$, a highly significant main effect of delay, $F(3,240)=5.85, p=.001 \eta_{\mathrm{p}}{ }^{2}=.072$, and a nonsignificant ongoing task by delay interaction, $F(6,240)=.39, p=.885, \eta_{\mathrm{p}}{ }^{2}=.010$. Figure 2 presents the accuracy means for the main effect of ongoing task type; post hoc analyses showing significant differences between the living/non-living and sentence verification task $(p=.001)$, with living/non-living being higher, between the living/non-living and the vowels task $(p=.035)$, with living/non-living being higher, but not for the sentence verification and vowels task $(p=.487)$. Figure 3 presents the accuracy means for the main effect of delay; further post hoc analyses revealed a highly significant difference between the 1 minute and 5 minute delays $(p=.004)$, with 1 minute being higher, as well as between the 30 seconds and 5 minute delays $(p=.004)$, with 30 seconds being higher, but not between the 30 seconds and 1 minute delays $(p>.999), 30$ seconds and 3 minute delays $(p=.191), 1$ minute and 3 minute delays $(p=.191)$, and 3 minute and 5 minute delays $(p>$.999). Please refer to the General Discussion for further interpretations of these results. 


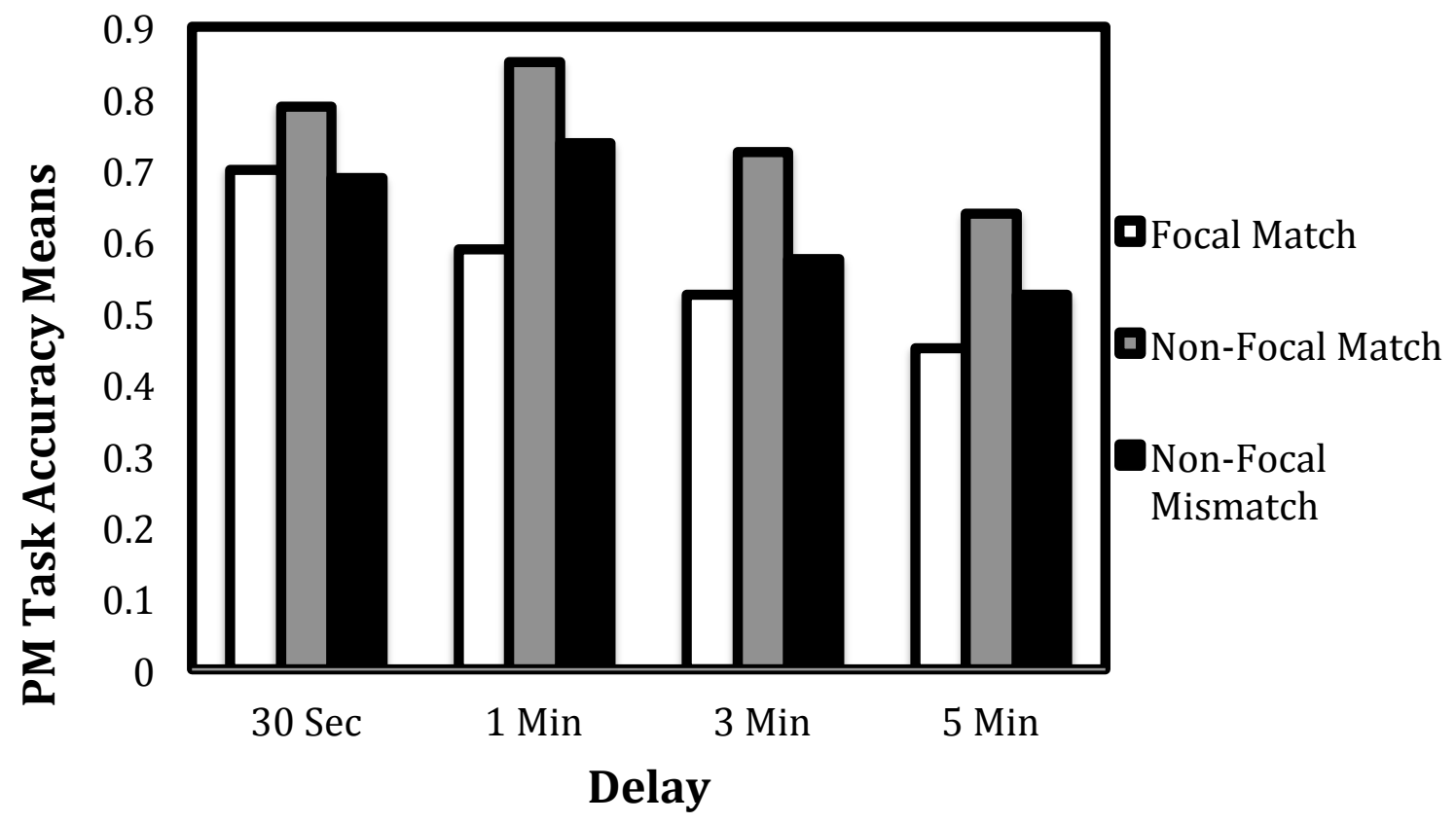

Figure 1. Prospective Memory Accuracy for Ongoing Task by Delay.

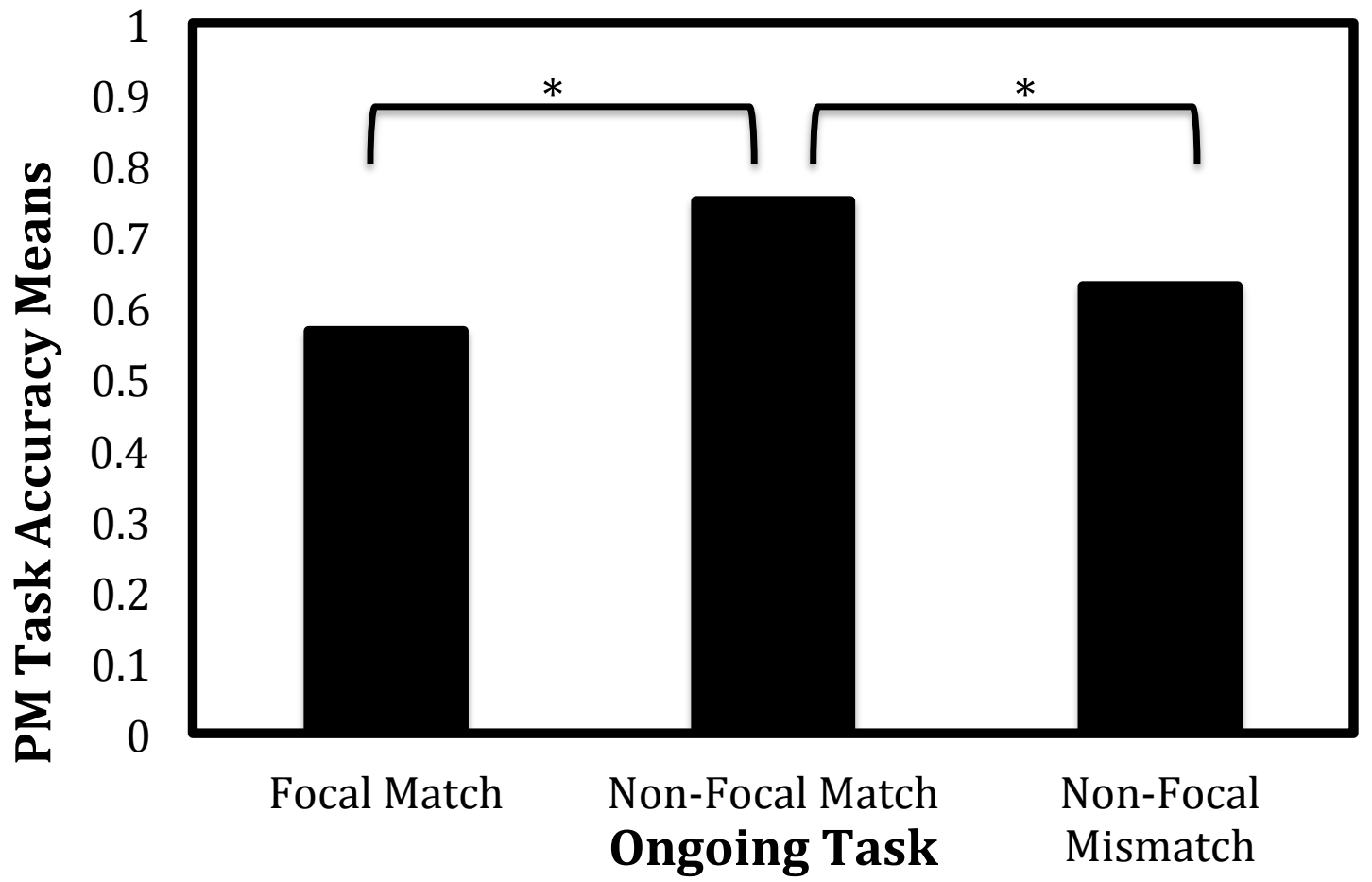

Figure 2. Prospective Memory Accuracy by Ongoing Task, ${ }^{*} p<.001$. 


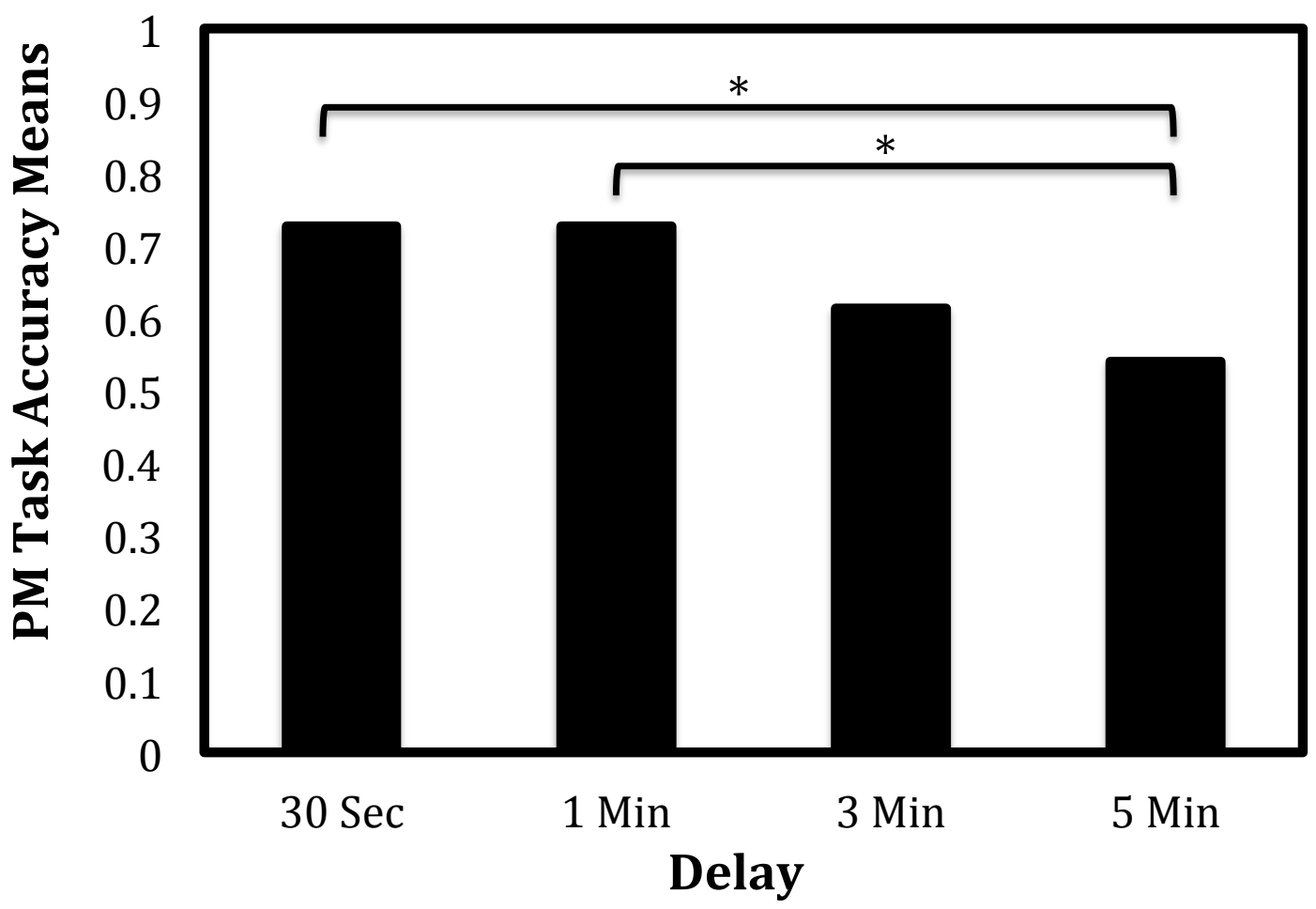

Figure 3. Prospective Memory Accuracy by Delay, ${ }^{*} p=.004$.

Table 1. Mean prospective memory accuracy for ongoing task by delay conditions

\begin{tabular}{llll}
$\begin{array}{l}\text { Ongoing } \\
\text { Task }\end{array}$ & Delay & Mean & $\begin{array}{c}\text { Std. } \\
\text { Deviation }\end{array}$ \\
\hline & $\begin{array}{l}30 \\
\text { seconds }\end{array}$ & 0.7 & 0.35 \\
\cline { 2 - 4 } $\begin{array}{l}\text { Focal } \\
\text { Match }\end{array}$ & 3 minute & 0.59 & 0.33 \\
\cline { 2 - 4 } & 5 minutes & 0.53 & 0.37 \\
\hline & $\begin{array}{l}30 \\
\text { seconds }\end{array}$ & 0.79 & 0.32 \\
\cline { 2 - 4 } $\begin{array}{l}\text { Non- } \\
\text { Focal } \\
\text { Match }\end{array}$ & 3 minute & 0.85 & 0.19 \\
\cline { 2 - 4 } & 5 minutes & 0.73 & 0.26 \\
\hline $\begin{array}{l}\text { Non- } \\
\text { Focal }\end{array}$ & $\begin{array}{l}30 \\
\text { seconds }\end{array}$ & 0.69 & 0.24 \\
\hline
\end{tabular}




\begin{tabular}{cccc} 
Mismatch & 1 minute & 0.74 & 0.17 \\
\cline { 2 - 4 } & 3 minutes & 0.58 & 0.33 \\
\cline { 2 - 4 } 5 minutes & 0.53 & 0.36 \\
\hline
\end{tabular}

\section{Ongoing Task Accuracy}

In order to assess the differences in ongoing task accuracy by block, a three-way repeated measures ANOVA was conducted. The results showed a highly significant main effect for ongoing task, $F(2,286)=8.97, p<.001, \eta_{\mathrm{p}}{ }^{2}=.059$, a non-significant main effect of delay, $F(4,286)=.419, p=.795, \eta_{\mathrm{p}}{ }^{2}=.006$, and a non-significant ongoing task by delay interaction, $F(8,286)=1.145, p=.333, \eta_{\mathrm{p}}{ }^{2}=.031$. Post hoc analyses revealed significant differences between the living/non-living and sentence verification task ( $p=$ .002 ), with sentence verification being higher, as well as between sentence verification and vowels task $(p=.001)$, with sentence verification being higher, but not for the living/non-living and the vowels task $(p>.999)$. Please refer to the General Discussion chapter for further interpretations of these results.

\section{Ongoing Task Reaction Times}

In order to assess the differences in the Baseline Block reaction times across ongoing tasks, a two-way ANOVA was conducted for the ongoing task and delay factors (Table 2). The justification for this analysis was to be certain they were consistent across all conditions; since the baselines were found to not be consistent across conditions, they were used as a covariate in an ANCOVA. 
Table 2. Mean Baseline Block reaction times for ongoing task by delay conditions

\begin{tabular}{|c|c|c|c|}
\hline $\begin{array}{l}\text { Ongoing } \\
\text { Task }\end{array}$ & Delay & Mean & $\begin{array}{c}\text { Std. } \\
\text { Deviation }\end{array}$ \\
\hline \multirow{5}{*}{$\begin{array}{l}\text { Focal } \\
\text { Match }\end{array}$} & 30 seconds & 1584.8 & 405.19 \\
\hline & 1 minute & 1415.1 & 233.27 \\
\hline & 3 minutes & 1522.05 & 312.37 \\
\hline & 5 minutes & 1379.35 & 212.03 \\
\hline & $\begin{array}{l}\text { No PM } \\
\text { control }\end{array}$ & 1382.9 & 250.77 \\
\hline \multirow{5}{*}{$\begin{array}{l}\text { Non-Focal } \\
\text { Match }\end{array}$} & 30 seconds & 949.5 & 156.32 \\
\hline & 1 minute & 1020.45 & 249 \\
\hline & 3 minutes & 997.25 & 180.46 \\
\hline & 5 minutes & 964 & 211.08 \\
\hline & $\begin{array}{l}\text { No PM } \\
\text { control }\end{array}$ & 836.24 & 196.27 \\
\hline \multirow{5}{*}{$\begin{array}{l}\text { Non-Focal } \\
\text { Mismatch }\end{array}$} & 30 seconds & 1083.7 & 281.75 \\
\hline & 1 minute & 1270.5 & 415.19 \\
\hline & 3 minutes & 1174.35 & 286.74 \\
\hline & 5 minutes & 1130.15 & 227.94 \\
\hline & $\begin{array}{l}\text { No PM } \\
\text { control }\end{array}$ & 968.5 & 212.75 \\
\hline
\end{tabular}




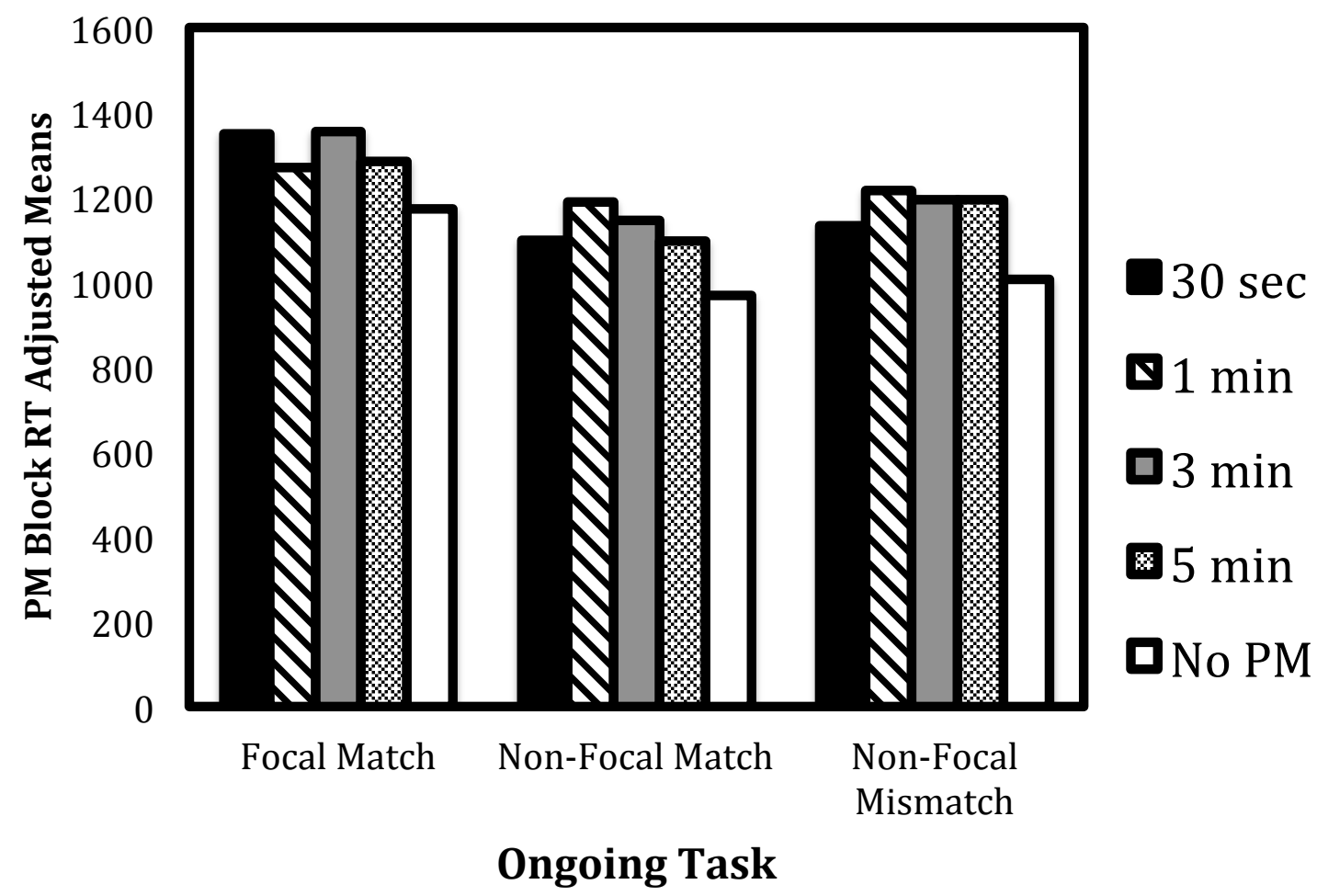

Figure 4. Adjusted Means for Prospective Memory Block Reaction Times for Ongoing Task by Delay.

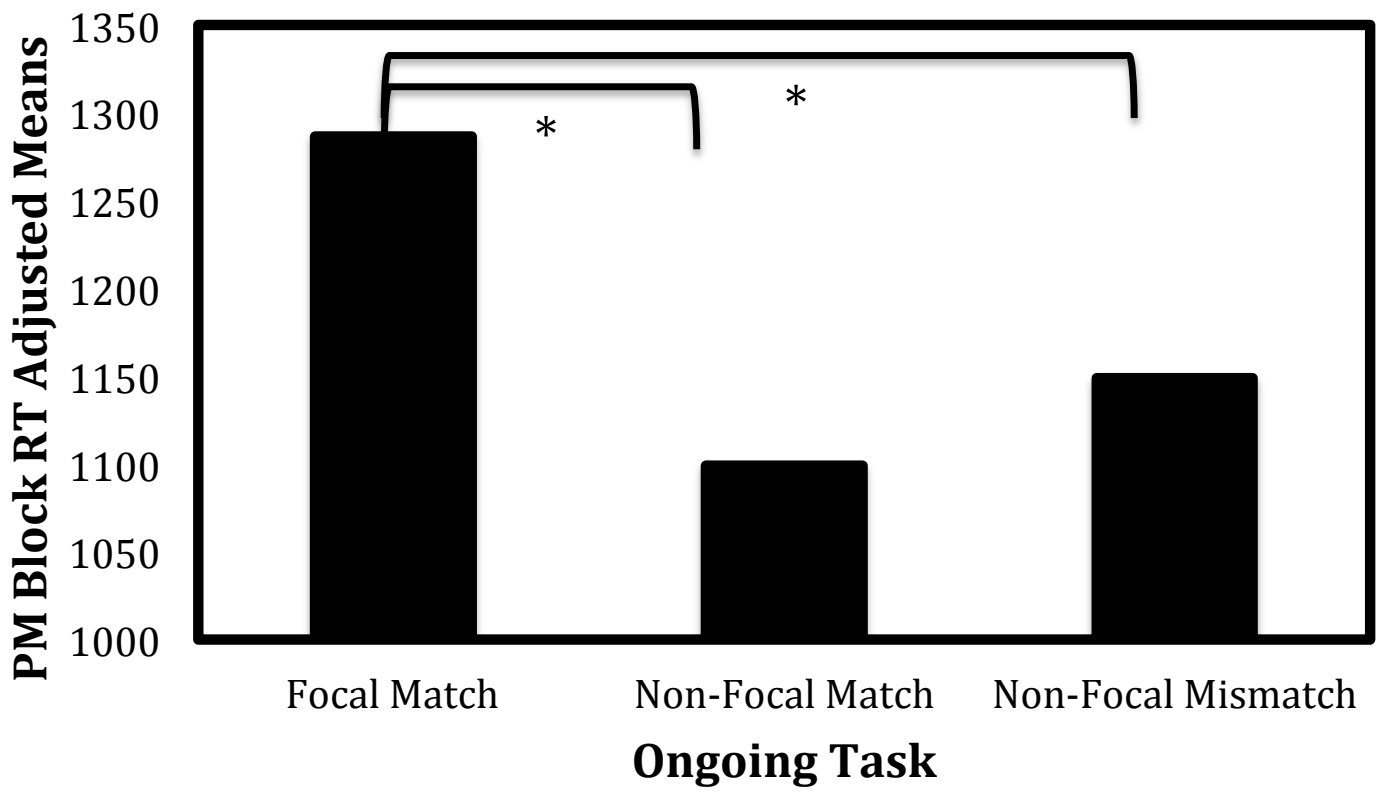

Figure 5. Prospective Memory Block Reaction Times by Ongoing Task, ${ }^{*} p<.001$. 


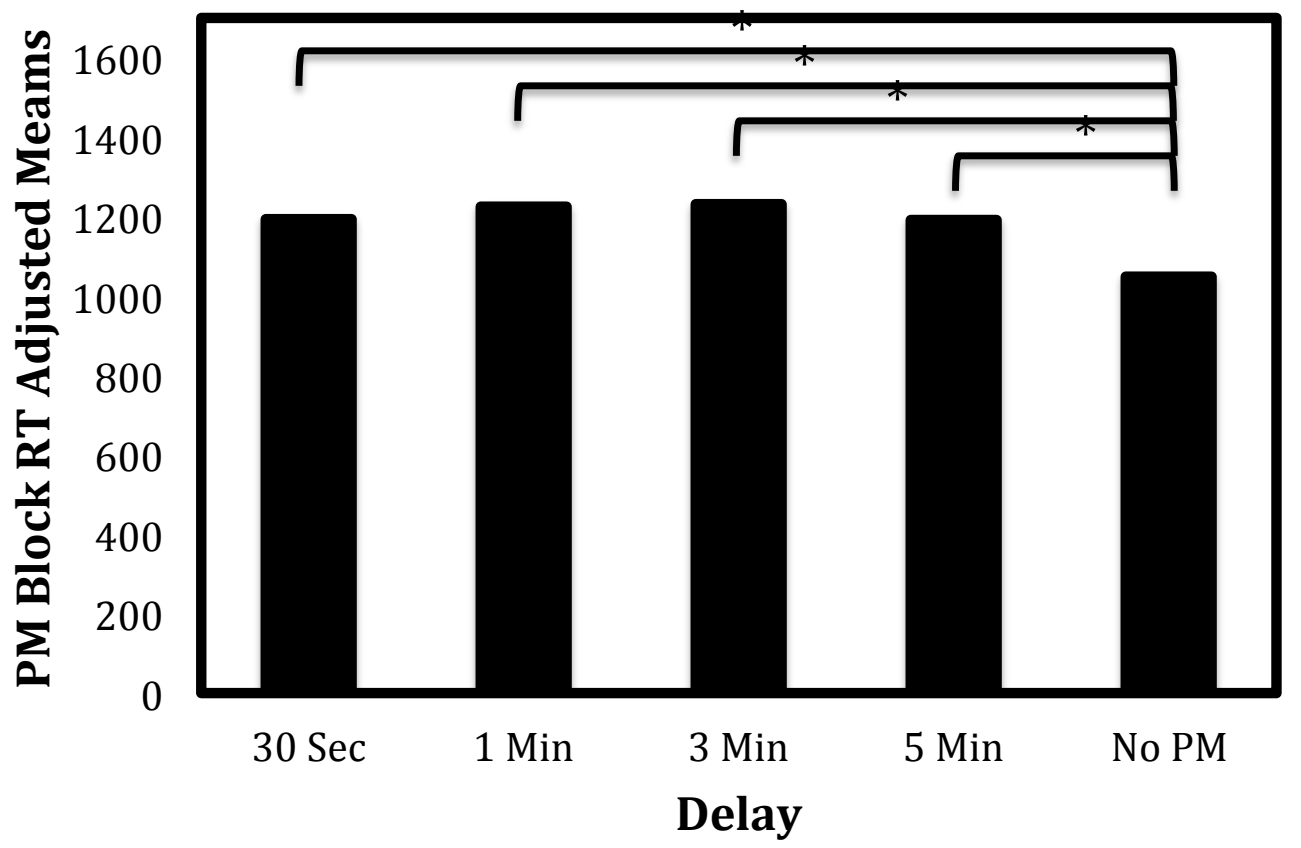

Figure 6. Adjusted Means for Prospective Memory Block Reaction Times by Delay, $p<$ .001 .

The differences observed in the baseline block across the various delays served as the basis for using an ANCOVA, with ongoing task and delay as factors and baseline reaction times as the covariate. Table 3 and Figure 4 present the adjusted mean reaction times for all of the conditions, showing a highly significant main effect of delay, $F(4,301)$ $=11.069, p<.001, \eta_{\mathrm{p}}{ }^{2}=.134$, a highly significant main effect of ongoing task, $F(2,301)$ $=21.736, p<.001, \eta_{\mathrm{p}}{ }^{2}=.132$, and a non-significant ongoing task by delay interaction, $F(8,301)=.99, p=.444, \eta_{\mathrm{p}}{ }^{2}=.027$. 
Table 3. Adjusted means of PM Block reaction time for ongoing task by delay

\begin{tabular}{|c|c|c|c|c|c|}
\hline \multirow{2}{*}{$\begin{array}{l}\text { Ongoing } \\
\text { Task }\end{array}$} & \multirow{2}{*}{ Delay } & \multirow{2}{*}{ Mean } & \multirow{2}{*}{ Std. Error } & \multicolumn{2}{|c|}{$\begin{array}{c}95 \% \text { Confidence } \\
\text { Interval }\end{array}$} \\
\hline & & & & $\begin{array}{l}\text { Lower } \\
\text { Bound }\end{array}$ & $\begin{array}{l}\text { Upper } \\
\text { Bound }\end{array}$ \\
\hline \multirow{5}{*}{$\begin{array}{l}\text { Focal } \\
\text { Match }\end{array}$} & 30 seconds & 1350.09 & 40.82 & 1269.75 & 1430.43 \\
\hline & 1 minute & 1270.16 & 39.7 & 1192.03 & 1348.3 \\
\hline & 3 minutes & 1354.68 & 39.93 & 1276.08 & 1433.27 \\
\hline & 5 minutes & 1285.46 & 39.29 & 1208.13 & 1362.79 \\
\hline & $\begin{array}{l}\text { No PM } \\
\text { control }\end{array}$ & 1172.70 & 40.46 & 1093.06 & 1252.34 \\
\hline \multirow{5}{*}{$\begin{array}{l}\text { Non-Focal } \\
\text { Match }\end{array}$} & 30 seconds & 1098.34 & 39.73 & 1020.13 & 1176.55 \\
\hline & 1 minute & 1188.50 & 39.94 & 1109.89 & 1267.11 \\
\hline & 3 minutes & 1145.63 & 39.73 & 1067.43 & 1223.82 \\
\hline & 5 minutes & 1095.56 & 39.57 & 1017.67 & 1173.45 \\
\hline & $\begin{array}{l}\text { No PM } \\
\text { control }\end{array}$ & 967.86 & 38.65 & 891.79 & 1043.93 \\
\hline \multirow{5}{*}{$\begin{array}{l}\text { Non-Focal } \\
\text { Mismatch }\end{array}$} & 30 seconds & 1132.96 & 39.07 & 1056.06 & 1209.86 \\
\hline & 1 minute & 1216.24 & 39.09 & 1139.3 & 1293.17 \\
\hline & 3 minutes & 1193.54 & 39 & 1116.78 & 1270.3 \\
\hline & 5 minutes & 1194.68 & 39.13 & 1117.66 & 1271.69 \\
\hline & $\begin{array}{l}\text { No PM } \\
\text { control }\end{array}$ & 1005.87 & 39.03 & 929.04 & 1082.71 \\
\hline
\end{tabular}

Table 4 and Figure 5 present the adjusted means for ongoing task type; post hoc analyses for the ongoing task type main effect revealed significant differences between the living/non-living and sentence verification task $(p<.001)$, with sentence verification being higher, and for the sentence verification and vowels task, with sentence verification 
being higher $(p<.001)$. Further, the sentence verification task showed longer RTs in both cases, but not between the living/non-living and the vowels task ( $p=.157)$.

Table 4. Adjusted means of PM Block reaction times by ongoing task

\begin{tabular}{lcccc} 
& & & \multicolumn{2}{c}{$\begin{array}{c}95 \% \text { Confidence } \\
\text { Interval }\end{array}$} \\
\cline { 4 - 5 } \begin{tabular}{l} 
Task \\
\cline { 4 - 5 }
\end{tabular} & Mean & Std. Error & $\begin{array}{c}\text { Lower } \\
\text { Bound }\end{array}$ & $\begin{array}{c}\text { Upper } \\
\text { Bound }\end{array}$ \\
\hline $\begin{array}{l}\text { Focal } \\
\text { Match }\end{array}$ & 1286.61 & 19.52 & 1248.21 & 1325.03 \\
\hline $\begin{array}{l}\text { Non-Focal } \\
\text { Match }\end{array}$ & 1099.17 & 18.91 & 1061.97 & 1136.39 \\
\hline $\begin{array}{l}\text { Non-Focal } \\
\text { Mismatch }\end{array}$ & 1148.66 & 17.48 & 1114.26 & 1183.06
\end{tabular}

Table 5. Adjusted means of PM Block reaction times by delay

\begin{tabular}{llccc} 
& \multirow{2}{*}{ Delay } & \multirow{2}{*}{ Mean } & \multicolumn{3}{c}{$\begin{array}{c}\text { S5\% Confidence } \\
\text { Interval }\end{array}$} \\
\cline { 4 - 5 } & & & $\begin{array}{l}\text { Lower } \\
\text { Bound }\end{array}$ & $\begin{array}{c}\text { Upper } \\
\text { Bound }\end{array}$ \\
\hline 30 seconds & 1193.80 & 22.52 & 1149.47 & 1238.12 \\
\hline 1 minute & 1224.97 & 22.52 & 1180.65 & 1269.28 \\
\hline 3 minutes & 1231.28 & 22.51 & 1186.98 & 1275.59 \\
\hline 5 minutes & 1191.90 & 22.58 & 1147.46 & 1236.34 \\
\hline $\begin{array}{l}\text { No PM } \\
\text { control }\end{array}$ & 1048.81 & 22.34 & 1004.84 & 1092.79
\end{tabular}


Table 6. Post hoc analyses for mean difference of PM Block reaction time data by ongoing task, * $p<.05$.

\begin{tabular}{llccc} 
& & \multicolumn{1}{c}{$\begin{array}{c}\text { Mean } \\
\text { Difference }\end{array}$} & Std. Error & $p$ value \\
\cline { 2 - 2 } Focal Match & Non-Focal Match & $187.44^{*}$ & 29.49 & $>.001$ \\
\cline { 2 - 2 } $\begin{array}{llll}\text { Non-Focal } \\
\text { Mismatch }\end{array}$ & Non-Focal Mismatch & $137.96^{*}$ & 26.59 & $>.001$ \\
\cline { 1 - 2 } & & 49.48 & 25.39 & 0.157
\end{tabular}

Table 7. Post hoc analyses for mean difference PM Block reaction time data by delay, * $p$ $<.05$.

\begin{tabular}{|c|c|c|c|}
\hline \multirow[b]{2}{*}{$\begin{array}{l}30 \\
\text { Seconds }\end{array}$} & \multirow[b]{2}{*}{$\begin{array}{l}\text { No PM } \\
\text { control }\end{array}$} & $\begin{array}{c}\text { Mean } \\
\text { Difference }\end{array}$ & Std. Error \\
\hline & & $144.99^{*}$ & 31.71 \\
\hline \multirow{2}{*}{1 minute } & 30 seconds & 31.17 & 31.83 \\
\hline & $\begin{array}{l}\text { No PM } \\
\text { control }\end{array}$ & $176.15^{*}$ & 31.71 \\
\hline \multirow{4}{*}{3 minutes } & 30 seconds & 37.49 & 31.84 \\
\hline & 1 minute & 6.31 & 31.84 \\
\hline & 5 minutes & 39.38 & 31.88 \\
\hline & $\begin{array}{l}\text { No PM } \\
\text { control }\end{array}$ & $182.47^{*}$ & 31.71 \\
\hline \multirow{3}{*}{5 minutes } & 30 seconds & -1.9 & 31.92 \\
\hline & 1 minute & -33.07 & 31.92 \\
\hline & $\begin{array}{l}\text { No PM } \\
\text { control }\end{array}$ & $143.09^{*}$ & 31.8 \\
\hline
\end{tabular}

Table 6 and Figure 6 present the adjusted RTs over the delay condition. Further post-hoc analyses for the delay main effect revealed significant differences between the No PM control and 30 seconds $(M=144.983, S E=31.706, p<.001)$, between the No 
PM control and 1 minute $(M=176.153, S E=31.707, p=.001)$, between the No PM control and 3 minutes $(M=182.467, S E=31.714, p=.001)$, and between the No PM control and 5 minutes $(M=143.085, S E 31.801, p=.001)$; no other differences were significant (all p's > .99); Table 7 presents the post hoc analysis RTs over the delay conditions. Please refer to the General Discussion chapter for further interpretations of these results. 


\section{CHAPTER IV \\ GENERAL DISCUSSION}

In the current study, a match in processing and the focality of the items processed were manipulated simultaneously, similar to the manipulation utilized in the McBride and Abney (2012) study. By altering the nature of the ongoing tasks with a single PM task embedded in these ongoing tasks, PM performance was expected to change based on the degree of overlap in the tasks. We created a focal match condition, which we expected to result in the highest overlap in processing for both the ongoing and PM tasks.

Additionally, the non-focal match condition contained less overlap and was expected to result in poorer performance compared to the focal match condition. Lastly, the non-focal mismatch condition involved no overlap in processing and was expected to result in the lowest performance compared to the focal match and non-focal match conditions.

\section{Paramount Findings}

The results showed that the overall PM accuracy for all PM task subjects decreased considerably with delay but not in the pattern expected. Initially, we expected that the PM accuracy for the Focal Match condition would be significantly higher than the Non-Focal Match and Non-Focal Mismatch conditions. It was hypothesized that (1) overall PM accuracy would be highest in the focal/match conditions and to decline less with delay than the other conditions; this hypothesis is grounded in the MP view, which states that focal tasks should have higher PM performance (Einstein \& McDaniel, 2000), 
as well as the TAP view, which states that a match in processing should have higher PM performance, as well (Meiser \& Graf 2000).

Additionally, it was hypothesized that (2) the overall PM cost (e.g., ongoing task speed) would decrease with delay due to decreased monitoring in longer delays and to decrease most rapidly for the focal-match condition. Since monitoring for a PM cue requires resource-demanding attention, monitoring should occur less during longer time intervals between PM instruction and PM cue presentation.

Also, we expected that PM accuracy would decline less with delay for the Focal Match condition compared to the Non-Focal Match and Non-Focal Mismatch conditions. It was found that those in the non-focal match conditions performed better than those in the non-focal mismatch conditions, a finding that is highly consistent with the TAP view on prospective memory performance (Morris et al., 1977). However, no advantage in PM performance was seen for the Focal Match condition; furthermore, the participants had the lowest PM accuracy compared to all other conditions. Additionally, the PM accuracy across all three ongoing tasks was much lower than expected (e.g., 70\% compared to 9095\% PM accuracy that is typically found in other research using similar tasks). This finding could have been due to the subjects' inexperience with computer-based experiments, low motivation to complete a more difficult task or even inattention to specific details within the instructions, which they did not adhere to (e.g., complete PM task in addition to ongoing task). While the experiment did not take any longer than 15 minutes per subject, the experiment may have been more challenging to the subjects than previously anticipated, despite pilot testing prior to data collection. The overall low PM 
accuracy across all conditions may serve as an additional limitation to the generalizations made for findings generated by the current experiment.

According to the TAP view, memory is enhanced when similar processing occurs during the study and test phases. When the TAP view is applied to PM, the view suggests that the degree of overlap in processing between the ongoing task and the PM task influences PM performance (Maylor, 1996); this overlap in processing prompts automatic processing of the PM target words. Thus, the TAP view predicts better PM performance when there is an overlap in processing between the PM task and the ongoing task; a finding supported by the results of the current experiment (i.e., match conditions vs. mismatch conditions.

According to the MP view, prospective memory retrieval can occur spontaneously in some cases in the absence of monitoring when a PM cue is presented and that the PM cue prompts the subjects to spontaneously retrieve the PM task instruction, which does not require preparatory attention (Einstein \& McDaniel, 2005). A key aspect of the MP view is defining the conditions under which spontaneous retrieval can be relied upon for completion of the PM task. Einstein and McDaniel (2005) state that the focality of the PM task plays an important role in the use of spontaneous retrieval for successful PM task performance. The results generated from the current experiment do not offer support in favor of the MP view, possibly due to the inconsistency of ongoing tasks, specifically in regards to the Focal Match condition. During this ongoing task, the subjects viewed a short sentence that needed to be read in its entirety. Further, each sentence verification trial was much longer and took more time to respond to compared to the living/non-living and vowel counting tasks. Additionally, the low PM accuracy could have been due to 
subjects' inability to follow directions closely enough to complete the experiment correctly, despite trimming the data for outliers. This unexpected result will be discussed further below.

Hypothesized 2 stated that the overall PM cost (e.g., ongoing task speed) would decrease with delay due to decreased monitoring in longer delays and to decrease most rapidly for the focal-match condition; while this result was not found by McBride and Abney (2012), it is still consistent with the MP view of PM. According to the PAM view of PM, a PM cost could be caused by individuals monitoring, or seeking out, cues to aid in the completion of the additional task. If a PM cost occurred, it would show evidence of slower reaction times and lower accuracy of the ongoing task (Smith, 2007). This PM cost to the ongoing task should always be present and is predicted for any PM task, regardless of the connection between the PM and ongoing tasks.

Monitoring was observed at all delay intervals (i.e., observed significant differences between no PM control and PM task conditions) showing constant, focused attention towards the PM task. To clarify, subjects completed the second block in the noPM control (i.e., completing two blocks of just the ongoing task) faster than any other PM condition (please refer to Figures 1-3); this finding specifically is consistent with the PAM view of PM.

It was expected that the overall PM cost (e.g., ongoing task speed) would decrease with delay due to decreased monitoring at longer delays and to decrease most rapidly for the focal-match condition. According to the PAM theory, the retrieval of a prospective memory continuously requires resource-demanding preparatory attentional processes, or effortful and deliberate focus (Smith, 2007). However, the MP view states that 
monitoring is not always necessary and that a PM cue can prompt spontaneous retrieval of the PM instruction under focal conditions (Einstein \& McDaniel, 2005). Further, Scullin et al. (2009) argue that since strategic monitoring can be an inefficient tool, spontaneous retrieval can occur after monitoring has stopped. The results of the current study were expected to show more strategic monitoring for the shorter delays and more spontaneous retrieval for the longer delays (McBride et al., 2011). In accordance with Scullin et al. (2009), we originally hypothesized that monitoring should only be present at short delays and that it would be maladaptive to monitor continuously, thus leaving spontaneous retrieval to bolster prospective memory performance at longer delays.

The most paramount findings from the current study are as follows. Subjects had higher PM accuracy on the Non-Focal Match condition compared to the Non-Focal Mismatch condition, which strongly supports the TAP view of prospective memory. In regards to delay, subjects had generally higher PM accuracy at the shorter PM delays compared to the longer PM delays.

After analyzing and interpreting these results, we came to the conclusion that an initial design flaw could have produced some of these unexpected findings, specifically in regards to the focal match ongoing task. The utilization of the sentence verification task is not completely novel to prospective memory research, but in this case, it was too inconsistent of a condition compared to the other two ongoing tasks. This was apparent after examining reaction time data and noticing that those who completed the sentence verification task took more time to complete the ongoing task alone. The sentence verification task may have made spontaneous retrieval more difficult given that each trial involved several words, but for the other ongoing tasks, only one word was presented. 
Previous research (McBride \& Abney, 2012) has demonstrated a strong PM advantage with focal match conditions when compared to non-focal match and non-focal mismatch performance. Unfortunately, the current results are not consistent with those of McBride and Abney (2012), likely due to the difference in tasks used in the two studies (i.e., their conceptual/perceptual overlap between tasks compared to our match/mismatch overlap between tasks). Another limitation of the sentence verification task was that previous research has found a focal advantage when using other forms of ongoing tasks (e.g., change in background, look for a face with eyeglasses, number of syllables in a word, counting vowels, living/non-living judgments, and identifying animal items), which were not found in the current study (McBride \& Abney, 2012; Einstein \& McDaniel, 2005).

\section{Summary of Current Study}

There are several implications of the findings of the current study. First, the overlap in processing between the study and test phase (i.e., TAP view) can play a significant role in PM performance, as demonstrated in the current study, as well as the original research of Morris et al. (1977), which was later expanded upon by Meier and Graf (2000) for PM tasks. The results generated in the current study from ongoing task accuracy and reaction times, as well as PM accuracy and reaction times, demonstrated support for both the TAP and PAM views, since subjects utilized monitoring and performed better when there was a match in processing. Further, these results do not offer support in favor of the MP view of prospective memory, since no evidence of spontaneous retrieval was obtained. It can be speculated that the design of the study was not conducive for spontaneous retrieval to occur, making any such potential findings 
difficult to rationalize. The findings show that an overlap in processing between a study phase and a test phase (TAP view) can help to boost PM performance and that monitoring is a much stronger force than previously anticipated, since monitoring was observed in all PM task conditions when compared to the no PM control condition (PAM view).

The original goal of the current study was to create a continuum of overlapping conditions (Focal Match, Non-Focal Match, and Non-Focal-Mismatch) in terms of processing type. Since the MP view was not supported in regards to the focality of processing, further testing is warranted. Specifically, the focal match ongoing task would need to be changed to something simpler and consistent with other ongoing tasks; this would provide a further test of the predictions regarding these conditions.

The reaction time data showed that those subjects who completed the sentence verification task (i.e., Focal Match) took more time to complete the ongoing task alone. Thus, the sentence verification task may have made spontaneous retrieval more difficult given that each trial involved several words, but for the other ongoing tasks, only one word was presented. Since this task took longer and required more effortful processing to complete, the subjects may have thought that the task was more important than the others since they had to put more effort towards it and had less available cognitive resources. These findings limit our ability to find spontaneous retrieval in the focal task where we expected to find it. While support in favor of the MP view was not found, there is a strong possibility that the current study was not a suitable test to be able to find spontaneous retrieval. 
Nonetheless, we have provided partial support for the TAP view of prospective memory, specifically in regards to both non-focal conditions when compared to focal conditions, (i.e., higher PM performance for the Non-Focal Match than Non-Focal Mismatch condition). We still expect that by combining a match in processing (i.e., MP view) with an overlap in processing (i.e., TAP view), optimum prospective memory performance can occur.

It can be concluded from this study that matching the processing that occurs during a study and test phase (i.e., baseline block and PM block) can improve prospective memory performance, consistent with the TAP view of PM. Further, it can be concluded that remembering to perform an additional task, regardless of the task, requires substantially more effort than performing the task alone (PAM view). The take away message from the current study is that studying and testing under the same conditions will provide the best prospective memory performance. It is also important to remember that adding an intention to perform an additional task in the future (i.e., a PM task) will interfere with one's ability to perform other tasks. 


\section{REFERENCES}

Abney, D. H., McBride, D. M., \& Petrella, S. N. (2013). Interactive effects in transferappropriate processing for event-based prospective memory: The roles of effort, ongoing task, and PM cue properties. Memory \& Cognition, 41,1032-1045.

Brewer, G. A. (2011). Analyzing response time distributions: Methodological and theoretical suggestions for prospective memory researchers. Journal of Psychology, 219, 117-124.

Einstein, G. O., \& McDaniel, M. A. (2005). Prospective memory: Multiple retrieval processes. Current Directions in Psychological Science, 14, 286-290.

Einstein, G. O., \& McDaniel, M. A. (2010). Prospective memory and what costs do not reveal about retrieval processes: A commentary on Smith, Hunt, McVay, and McConnell (2007). Journal of Experimental Psychology: Learning, Memory, and Cognition, 36, 1082-1088.

Einstein, G. O., McDaniel, M. A., Thomas, R., Mayfield, S., Shank, H., Morrisette, N., \& Breneiser, J. (2005). Multiple processes in prospective memory retrieval: Factors determining monitoring versus spontaneous retrieval. Journal of Experimental Psychology: General, 134, 327-342.

Marsh, R. L., Hicks, J. L., \& Cook, G. I. (2005). On the relationship between effort toward an ongoing task and cue detection in event-based prospective memory. Journal of Experimental Psychology: Learning, Memory, and Cognition, 31, 6875.

Marsh, R. L., Hicks, J. L., \& Hancock, T. W. (2000). On the interaction of ongoing cognitive activity and the nature of an event-based intention. Applied Cognitive Psychology, 14, S29-S41.

Maylor, E. A. (1996). Age-related impairment in an event-based prospective-memory task. Psychology and Aging, 11, 74-78.

Maylor, E. A., Darby, R. J., Logie, R. H., Della Sala, S., \& Smith, G. (2002). Prospective memory across the lifespan. In P. Graf \& N. Ohta (Eds.), Lifespan development of human memory (pp. 253-256). Cambridge, Massachusetts: MIT Press.

McBride, D. M., \& Abney, D. H. (2012). A comparison of transfer-appropriate processing and multi-process frameworks for prospective memory performance. Experimental Psychology, 59, 190-198.

McBride, D. M., Beckner, J. K., \& Abney, D. H. (2011). Effects of delay of prospective memory cues in ongoing task on prospective memory performance. Memory \& Cognition, 39, 1222-1231.

McDaniel, M. A., \& Einstein, G. O. (2000). Strategic and automatic processes in prospective memory retrieval: A multiprocess framework. Applied Cognitive Psychology, 14, S127-S144.

Meier, B., \& Graf, P. (2000). Transfer appropriate processing for prospective memory tests. Applied Cognitive Psychology, 14, S11-S27.

Meiser, T., \& Schult, J. C. (2008). On the automatic nature of the task-appropriate 
processing effect in event-based prospective memory. European Journal of Cognitive Psychology, 20, 290-311.

Morris, C. D., Bransford, J. D., \& Franks, J. J. (1977). Levels of processing versus transfer appropriate processing. Journal of Verbal Learning and Verbal Behavior, 16, 519-533.

Scullin, M. K., Einstein, G. O., \& McDaniel, M. A. (2009). Evidence for spontaneous retrieval of suspended but not finished prospective memories. Memory \& Cognition, 37, 425-433.

Smith, R. E. (2003). The cost of remembering to remember in event-based prospective memory: Investigating the capacity demands of delayed intention performance. Journal of Experimental Psychology: Learning, Memory, and Cognition, 29, 347361.

Smith, R. E. (2010). What costs do reveal and moving beyond the cost debate: Reply to Einstein and McDaniel. Journal of Experimental Psychology: Learning, Memory, \& Cognition, 36, 1089-1095.

Smith, R. E., \& Bayen, U. J. (2006). The source of adult age differences in event-based prospective memory: A multinomial modeling approach. Journal of Experimental Psychology: Learning, Memory, and Cognition, 32, 623-635.

Smith, R. E., Hunt, R. R., McVay, J. C., \& McConnell, M. D. (2007). The cost of eventbased prospective memory: Salient target events. Journal of Experimental Psychology: Learning, Memory, and Cognition, 33, 734-746.

West, R., \& Craik, F. I. M. (2001). Influences on the efficiency of prospective memory in younger and older adults. Psychology and Aging, 16, 682-696. 